DOI:

\title{
INNOVATIVE TECHNOLOGIES IN THE PRACTICE OF TEACHING FOREIGN LANGUAGES TO STUDENTS OF MEDICAL UNIVERSITIES
}

\author{
Tamara Kyrik \\ Candidate of Pedagogic Sciences, Associate professor \\ Kyiv Medical University \\ (Kyiv, Ukraian) \\ e-mail: t.kiryk@kmu.edu.ua \\ Maryna Boholiubova \\ Senior Lecturer \\ Kyiv Medical University \\ (Kyiv, Ukraian) \\ e-mail: astoret2015@gmail.com \\ Olga Lyalina \\ Senior Lecturer \\ Kyiv Medical University \\ (Kyiv, Ukraian) \\ e-mail: $\underline{\text { imsd@,kmu.edu.ua }}$
}

\begin{abstract}
Kiev Medical University was established in 1992. Today it is one of the largest Ukrainian private universities. Cultural and humanitarian training at the university is carried out by the department of foreign languages and social and humanitarian disciplines. Teaching is conducted in Ukrainian and English. The modernization of the educational process is an urgent problem. The process of training and education of student youth should reflect the essential sociocultural processes, therefore, innovative technologies are implemented in the educational process, a special place belongs to media education technologies.
\end{abstract}

Keywords: higher medical education, teaching foreign languages, Wikididactics, blodidactics, medical blodidactics, innovative technologies

\section{ИННОВАЦИОННЫЕ ТЕХНОЛОГИИ В ПРАКТИКЕ ПРЕПОДАВАНИЯ ИНОСТРАННЫХ ЯЗЫКОВ СТУДЕНТАМ МЕДИЦИНСКОГО УНИВЕРСИТЕТА}

\author{
Тамара Викторовна Кирик \\ Канд. педаг. наук, доцент, зав кафедрой \\ Киевский медицинский институт \\ (Киев, Украина) \\ e-mail: t.kiryk@kmu.edu.ua \\ Боголюбова Марина Михайловна \\ Старший преподаватель \\ Киевский медицинский институт \\ (Киев, Украина) \\ e-mail: astoret2015@gmail.com \\ Ольга Александровна Лялина \\ Старший преподаватель \\ Киевский медицинский институт \\ (Киев, Украина) \\ e-mail: imsd@kmu.edu.ua
}

\begin{abstract}
Аннотация. Киевский медицинский университет создан в 1992 году. Сегодня это один из крупнейших украинских частных вузов. Культурно-гуманитарную подготовку в университете осуществляет кафедра иностранных языков и социальногуманитарных дисциплин. Преподавание ведется на украинском и английском языках. Осовременивание образовательного процесса является актуальной проблемой. Процесс обучения и воспитания студенческой молодежи должен отражать сущностные социокультурные процессы, потому в учебном процессе реализуются инновационные технологии, особое место принадлежит технологиям медиаобразования.
\end{abstract}

Ключевые слова: высшее медицинское образование, преподавание иностранных языков, викидидактика, блогодидактика, медицинская блогодидактика, инновационные технологии

Введение. Экспресс-опросы как форма определения духовных ориентиров студенческой молодежи. Киевский медицинский университет, созданный в 1992 году заслуженным врачом Украины, кандидатом медицинских наук, Генеральным директором Украинской ассоциации народной медицины В. В. Поканевичем 
(1950-2012г.г.), сегодня - один из крупнейших украинских частных вузов, единственное частное медицинское учебное заведение такого масштаба. Реализация авторской концепции нашла отражение в функционировании и развитии высшего медицинского учебного заведения нового типа. Сегодня Киевский медицинский университет - лидер среди частных вузов в Украине.

Сейчас в Университете обучается около 2600 человек, среди них 35\% - студенты-иностранцы из 56 стран мира (КМУ, эл.рессурс 2018; КМУ УАНМ. эл.рессурс 2018) Преподавание ведется на украинском и английском языках. Культурно-гуманитарную подготовку осуществляет кафедра иностранных языков и социально-гуманитарных дисциплин. В англоязычных группах все дисциплины читаются на английском, украинский изучается как иностранный. В группах отечественных студентов украинский язык изучается с учетом будущей специальности обучающися, обучение которых проходит в поликультурной среде. Осовременивание образовательного процесса в вузе является актуальной проблемой.

Остановимся на двух инновационных аспектах, использемых кафедрой в учебном процес

Анализ исследований и публикаций. Процесс обучения и воспитания студенческой молодежи должен отражать сущностные социокультурные процессы. Следит за ними помогают блиц-опросы. Например, на первых занятиях по украинскому языку в группах отечественных студентов им предлагается спонтанно написать десять имен выдающихся украинских деятелей, которые, по мнению опрошенных, олицетворяют Украину, явлются репрезентантами Украины и с кем, по мне нию студентов, в первую очередь следует знакомить представителей других культур Предлагается такжн назвать периодические издания, сайты, блоги, к которым обращаются студенты, утоляя «информационную жажду». Результаты опросов прорабатывают и объявляют сами студенты. Часто эти сообщения становятся основой для выступления на студенческих конференциях, публикуются (Onkovych Artyom 1996; Onkovych A.D 2002; Panchenko 2008)

Такие опросы - не новость. Например, в разделе «Персоналии - языковые знаки национальной культуры» в пособии «Українознавство і лінгводидактика» говорится об итогах подобных опросов, проведенных в девяностые годы прошлого века в нескольких украинских городах в среде студентов технических специальностей. По результатам опросов, группу лидеров возглавлял Тарас Шевченко, которого большинство студенческих экспертов считало символом, духом, оберегом нации. За ним - Леся Украинка, ее называли в числе лидеров $85 \%$ опрошенных в Одессе и 56,1\% - в Киеве. Десятка лидеров по рейтингу выглядела Тарас Шевченко, Леся Украинка, Иван Франко, Михаил Грушевский, Григорий Сковорода, Иван Мазепа и Лина Костенко, Богдан Хмельницкий, Николай Коцюбинский, Николай Лысенко (Onkovych Anna, Onkovych Artyom 2003:18). Почти каждый второй внес в свой список историка и общественного деятеля Михаила Грушевского, произведения которого в Украине до провозглашения независимости были запрещены. Это свидетельствовало о переоценке ориентаций и ценностей, о формировании новой иерархии, которая проходила в условиях нового социального выбора. В первой десятке находилась Лина Костенко - единственный представитель современности. Не всеми экспертами однозначно оценивалась роль в истории Украины Ивана Мазепы и Симона Петлюры. По рейтингу они занимали достаточно высокие позиции, опережая таких известных деятелей, как князь Ярослав Мудрый, кинорежиссер Александр Довженко, писатель Иван Котляревский и еще более 250 человек из общего списка называний (Onkovych G. 1997; Onkovych Anna, Onkovych Artyom 2003; Onkovych Anna 2003) В ряде публикаций характеризовались конкретные персоналии (Богдан Хмельницкий, Михаил Грушевский), которые рассматривались в кругу духовных ориентиров современной молодежи; (Onkovych Artyom 1996; Onkovych A.D 2002)

В сентябре 2007 г. такой опрос был проведен а группах студентов-первокурсников специальности «Издательское дело и редактирование» НТУ Украины «КПИ». В публикации Дианы Панченко в сборнике «Друкарство молоде» (Рanchenko 2008) указано: болем всего голосов отдано за Тараса Шевченко (96,82\%). На втором месте - Леся Украинка $(74,77 \%)$, на третьем - Иван Франко (65,07\%). За ними - выдающиеся государственные деятели: Богдан Хмельницкий (60,31\% - четвертая позиция), Виктор Ющенко (50,79\% пятая). Он - первый среди современников. На шестой позиции - Юлия Тимошенко и Михаил Грушевский (49,2\%), на седьмой - Лина Костенко (28,57\%), за ней - Ярослав Мудрый (26,98\%). Братья Кличко (25,39\%) занимали десятую позицию (все опрашиваемые отмечали именно обоих спортсменов). Так, в первой десятке самых известных соотечественников четверо - литераторы, пятеро - государственные деятели, двое спортсмены. Кстати, за братьями Кличко шли Андрей Шевченко и Григорий Сковорода - по 23,8\%. Также одинаковое количество баллов имели А.Довженко и И.Мазепа (17,46\%). Первой из представительниц шоубизнеса выступала Руслана Лыжичко (15,87\%), которая опережала поэта Василия Стуса и князя Владимира Великого (14,28\%). Дальше - (по 12,59\%) - И. Котляревский, В. Лобановский, В.Янукович и Вакарчук. 11,1\% называемые имели Чорновил, Я. Клочкова и Роксолана (Настя Лисовская) 9,52\% - Драгоманов и Винниченко; 7,93\% - Кравчук, Остап Вишня и Данилко ( «Сердючка») и М.Поплавский. Литераторы имели огромное влияние на общество. Результаты опроса отличались от результатов предыдущих лет, проводимых по методике Г.В.Онкович с начала 90-х годов. Неожиданным было количество современников во главе общего перечня персоналий, особенно - государственных деятелей, политиков.

Изложение основного материала.

Подобный опрос был проведен в сентябре 2018 и 2019 г.г. среди студентов-первокурсников нашего университета. Как и в предыдущие годы, в прошлом учебном году первое место в рейтинге занимал выдающийся украинский поэт Тарас Шевченко - 84,6\% студентов именно его назвали лидером нации. На второй позиции - Леся Украинка, Иван Франко и Григорий Сковорода - 69,2\% студентов включили их в свой список. Третье место занимает Богдан Хмельницкий (53,8\%). Далее - кинорежиссер Александр Довженко, наша 
современница Лина Костенко и историк, политический деятель Михаил Грушевский. Их назвали $38,4 \%$ студентов. На следующей позиции борцы за независимость Украины Симон Петлюра и поэт Василий Стус (30,7\%). Далее - поэт Владимир Сосюра, князь - киевский правитель и креститель Киевской Руси Владимир Великий, гетьман Иван Мазепа (23\%). За ними - Ярослав Мудрый, Степан Бандера, Владимир Кличко (15,4\%). Некоторые вспомнили представителей медицины: Николая Амосова, Николая Пирогова и Александра Богомольца. Были названы и современные спортсмены: Александра Усик, Андрей Шевченко, а также певцы Святослав Вакарчук и Кузьма Скрябин (анкеты обрабатывала студентка первого курса Анастасия Линченко). Поражало то, что список лидеров почти совпадал со списками 90-х годов (минимум современников, отсутствие государственников) и очень отличался от результатов «оранжевой волны» 10-летней давности. Результаты опроса этого года близки к прошлогодним. Правда, впервые в общем списке появился новоизбранный президент Владимир Зеленский (единичное называние), имени котрого ни в одном опросе прошлых лет не было.

Расширить знания о той или иной персоналии, которая является языковым знаком национальной культуры (Onkovych 1994, Onkovych G. 1996, Onkovych Artyom 1996), можно разными способами. В частности, можно предложить студентам назвать черты, наиболее присущие тому или иному деятелю, включенном в список персоналий, которые олицетворяют Украину, можно создать обобщенный портрет украинца, на которого ориентируется современная молодежь, можно поговорить о том, эти черты присущи только украинском или это - общечеловеческие добродетели, эти качества - врожденные или приобретенные системой воспитания (Onkovych Anna, Onkovych Artyom 2003:33). Студенческий выбор персоналий - тема для размышлений и коррекции во время занятий по дисциплинам социально-гуманитарного цикла.

Персоналии, которые олицетворяют Украину, - языковые знаки национальной культуры, благодатный материал для воспитания у молодежи лучших качеств. Убеждаемся в этом при проведении университетского этапа Международного литературного конкурса ученической и студенческой молодежи имени Тараса Шевченко. Главной его целью является чествование творческого наследия Т.Г.Шевченко, выявления творчески одаренной учащейся и студенческой молодежи и повышение уровня литературного образования в Украине и за ее пределами. Этот конкурс в КМУ проходит в два тура. На первом студенты пишут экспресс-эссе «Шевченко в кругу моих духовных ориентиров / приоритетов», читают произведения Кобзаря. На написание экспресс-эссе выделяется 15 минут. Тексты не могли быть слишком большими, поэтому на следующем занятии каждый студент озвучивал свое эссе, а товарищи по группе должны были выделить и охарактеризовать лучший текст. По итогам студенческих называний, определялся победитель в каждой группе, который должен был принять участие во втором туре. В прошлом году ими стали более 20 студентов, но до финиша (29 ноября) пришли Наталья Доброгивская, Юлия Савинова, Евгения Свистула, Михаил Фоменко, Юрий Ладнюк, Вадим Жвания, Елизавета Шевченко, Клим Золотарев, Михаил Яцентюк, Виктория Дудина.

Во второй тур студенты готовили самопрезентацию, декламировали свое любимое произведение Кобзаря. Праздничного настроения собравшимся добавили выступления иностранных студентов, которые читали «Завещание» Шевченко на разных языках: на азербайджанском, арабском, английском, французском, турецком. Студентка из Индии Преанджана проникновенно исполнила популярную современную украинскую песню «Плакала» на языке Тараса Шевченко. Эмоциональным был танец по сюжету поэмы «Катерина» в исполнении студентов университета Вадима Жвании и Даши Артемьевой. Настоящим украшением мероприятия была ведущая - першокусниця Амина Иршадова (Kirik, Nelovkina-Bernal’. Onkovych G.2018)

Международный литературный конкурс ученической и студенческой молодежи имени Тараса Шевченко в Киевском медицинском университете, инициированный кафедрой иностранных языков и социальногуманитарных дисциплин, превратился в настоящий праздник знаний, который объединил талантливую студенческую молодежь, преподавателей.

Конкурсная комиссия определила лучших участников, которые представляли университет на следующем этапе Международного литературного конкурса ученической и студенческой молодежи имени Тараса Шевченко. Присутствующие убедились в необходимости и возможности объединять общество вокруг национальной идеи, воспитывать у молодого поколения любовь к родному языку, способствовать росту авторитета Украины в мире.

Вывод.Экспресс-опросы, результаты которых обрабатывают и озвучивают сами студенты, могут быть эффективным источником осовременивания учебного процесса, его коррекции. Тот факт, что студенты почти не называют имен выдающихся медиков, ориентирует преподавателей на расстановку определенных профессионально-ориентированных акцентов на занятиях по языку и социально-гуманитарным дисицплинам.

\section{LIST OF REFERENCES}

Kiryk T. V., Nelovkina-Bernal' O. A., Onkovich G.V. Iz dosvidu osuchasnennya osvitn'ogo procesu v medichnomu vishi // Innovaciï ta tradiciï u movniy pidgotovci inozemnih studentiv: tezi dopovidey mizhnarodnogo naukovo-praktichnogo seminaru. - H. : Vidavnictvo Ivanchenka I. S., 2018. - 336 s.. - S.123 - 127.

Onkovich A. V. Personalii kak znaki nacional'noy kul'tury v formirovanii nacional'no-kul'turnogo komponenta kommunikativnoy kompetencii / A. V. Onkovich // IV Mezhdunar. simpozium po lingvostranovedeniyu, Moskva, 31 yanv.-4 fevr. 1994 g. : tez. dokl. i soobsch./ Mezhdunar. assoc. prepodavateley rus. yaz. i lit., Ros. fond mira, In-t rus. yaz. im. A. S. Pushkina. - M. : [IRYaP], 1994. S. $166-168$

Onkovich G. V. Slovo-tema yak zgornutiy nacional'no-kul'turniy tekst i metodika yogo aktualizaciï v auditoriï studentiv-inozemciv / G. V. Onkovich // Tekst i metodika ego analiza : materialy VII Mezhdunar. nauch. konf. Po problemam semant. issled. - Har'kov : [b. i.], 1994. - Ch. III. - S. 98-102. 
Onkovich G. V. Personaliï yak duhovni orientiri molodi / Galina [Ganna] Onkovich // Ridna shk. - 1996. - Lyut. (№ 2). - S. $32-34$. Onkovich G. V. Ukraïnoznavstvo i lingvodidaktika : navch. posib. / Ganna Onkovich ; Derzh. akad. keriv. kadriv osviti. - Kiïv : Logos, 1997. - 105 s. - S.16-33.

Onkovich Anna. Personalii kak duhovnye orientiry sovremennoy ukrainskoy molodezhi: smena stereotipov / Anna Onkovich, Artem Onkovich // Problemy współczesnej komparatystyki / Uniwersytet im. Adama Mickiewicza w Poznaniu, Instytut filologii rosyjskiej, zakład Komparatystyki Literasko-Kulturowej ; pod red. Haliny Chałacińskiej-Wiertelak i Wołodymyra Wasyłenki. - Poznań : UAM, 2003. - S. 259-263.

Onkovich Artem, Sluchevs'kiy Mihaylo, Cegel'nik Bogdan. Personaliya "Bogdan Hmel'nic'kiy” v koli duhovnih orientiriv suchasnoï molodi // Bogdan Hmel'nic'kiy yak istorichna postat' i literaturniy personazh / Vidp. za vipusk M. M. Kononchuk. - K.: Zhivicya, 1996. - S. 119-123.

Onkovich A.D. Personaliya "Mihaylo Grushevs'kiy" u koli duhovnih orientiriv suchasnoï molodi // Zbirnik naukovih prac' "Mihaylo Grushevs'kiy - naukovec' ta politik u konteksti suchasnosti” (do 135-ï richnici vid dnya narodzhennya). - K.: Ukraïns'ka vidavnicha spilka, 2002. - S. 353-360.

Panchenko Diana. Personaliï yak kod do rozuminnya nacional'nih cinnostey ta prioritetiv // Panchenko Diana. Drukarstvo molode: zbirnik materialiv students'koï konferenciï. - Kiïv: VPI NTU Ukraïni «KPI», 2008 r. Kiïvs'kiy medichniy universitet // [Elektronniy resurs] http://kmu.edu.ua/ / Data zvernennya: 30 listopada 2018 r. Kievskiy medicinskiy universitet UANM (KMU UANM) // [Elektronniy resurs] https://vuz.online.ua/region/10/302/. Data zvernennya: 30 listopada $2018 \mathrm{r}$.

\section{For citation:}

Kyrik Tamara, Boholiubova Maryna \& Lyalina Olga (2019) INNOVATIVE TECHNOLOGIES IN THE PRACTICE OF TEACHING FOREIGN LANGUAGES TO STUDENTS OF MEDICAL UNIVERSITIES // International Scientific-Pedagogical Organization of Philologists “WEST-EAST” (ISPOP). Scientific Journal WEST-EAST. Vol 2/1 N1 (October, 2019). p. 100-104. doi:

Для цитирования:

Кирик Т. В., Боголюбова М. М., Лялина О. А . (2019) ИННОВАЦИОННЫЕ ТЕХНОЛОГИИ В ПРАКТИКЕ ПРЕПОДАВАНИЯ ИНОСТРАННЫХ ЯЗЫКОВ СТУДЕНТАМ МЕДИЦИНСКОГО УНИВЕРСИТЕТА // Internationa 1Scientific-Pedagogical Organization of Philologists “WEST-EAST ” (ISPOP) . Scientific Journal WEST-EAST. Vol 1/1 N1 (October, 2019). C. 100-104. doi:

Information about the authors: Tamara Kyrik - Candidate of Pedagogic Sciences, Kyiv Medical University, Kyiv, Ukraian e-mail: $\underline{\text { imsd@kmu.edu.ua }}$

t.kiryk@kmu.edu.ua

Maryna Boholiubova - Senior Lecturer, Kyiv Medical University, Kyiv, Ukraian

e-mail: imsd@kmu.edu.ua

astoret2015@gmail.com

Olga Lyalina- Senior Lecturer, Kyiv Medical University, Kyiv, Ukraian

e-mail: $\underline{\text { imsd@kmu.edu.ua }}$

Сведения об авторах: Кирик Тамара Викторовна - канд. педаг. наук, доцент, зав кафедрой, Киевский медицинский институт, Киев, Украина

e-mail: e-mail: imsd@kmu.edu.ua

t.kiryk@kmu.edu.ua

Боголюбова Марина Михайловна - старший преподаватель, Киевский медицинский институт

(Киев, Украина)

e-mail:

Лялина Ольга Александровна - старший преподаватель, Киевский медицинский институт, Киев, Украина

e-mail: e-mail: $\underline{\text { imsd@kmu.edu.ua }}$ 